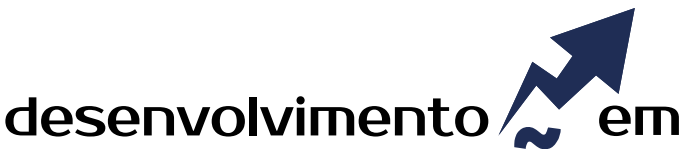 QUESTÃO
}

\section{Código Florestal e Pagamento por Serviços Ambientais Um Estudo de Caso com Base na Redução de Carbono Emitido e Abordagem Sistêmica das Unidades de Produção Agrícola}

\author{
http://dx.doi.org/10.21527/2237-6453.2019.48.213-230 \\ Recebido em: 5/12/2017 \\ Aceito em: 14/3/2019
}

\section{Leticia Andrea Chechi, ${ }^{1}$ Mariele Boscardin, ${ }^{2}$ Ana Luísa Araújo de Oliveira ${ }^{3}$}

\begin{abstract}
RESUMO
Com a revisão do Código Florestal, Lei no 12.651, de 25 de maio de 2012, uma das discussões que vêm recebendo destaque é a da instituição de um programa de Pagamento por Serviços Ambientais (PSA) para as áreas de conservação. Este trabalho objetiva apresentar uma proposição de PSA para uma propriedade da agricultura familiar de Esperança do Sul-RS, com base na redução de carbono emitido e abordagem sistêmica das unidades de produção agrícola, no contexto de adequação ao Código Florestal vigente no Brasil. Inicialmente foi realizada uma pesquisa documental sobre PSA, Código Florestal Brasileiro e as especificidades das propriedades da agricultura familiar nesse cenário, e optou-se pela realização de um estudo de caso. Na sequência foi selecionada uma propriedade de agricultura familiar no município de Esperança do Sul-RS que necessita de recuperação da Área de Preservação Permanente e apresenta área de reserva legal superior à exigida pelo Código Florestal. Nessa propriedade realizou-se o mapeamento da área, visita in loco para observação da mata nativa e levantamento de informações com o proprietário. Com base nessas informações e naquelas obtidas na pesquisa documental, realizou-se o cálculo da conservação do carbono e um diagnóstico dos sistemas de produção com base na abordagem sistêmica. 0 estudo de caso apontou para a importância de um PSA em propriedades de agricultura familiar, tendo como base a área de conservação existente, as emissões de carbono evitado, no caso de desmatamento, e o baixo custo em relação a uma possível recuperação da área. Para a agricultura familiar, o PSA poderia estimular a conservação dos recursos naturais, revelando-se este um custo inferior ao de recuperação florestal.
\end{abstract}

Palavras-chave: Pagamento por serviços ambientais. Agricultura familiar. Legislação ambiental. Abordagem sistêmica.

FOREST CODE AND ENVIRONMENTAL SERVICES PAYMENT: A CASE STUDY BASED ON CARBON REDUCTION EMITTED AND SYSTEMATIC APPROACH OF AGRICULTURAL PRODUCTION UNITS

\begin{abstract}
With the revision of the Forest Code, Law no. 12.651, of May 25, 2012, one of the discussions that has been highlighted is the implementation of a Payment for Environmental Services (PSA), program for conservation areas. This paper aims to present a PSA proposal for a family farm property in Esperança do Sul, RS, based on the reduction of carbon emitted and systemic approach of agricultural production units, in the context of compliance with the Forest Code in force in Brazil. Initially a documentary research on PSA, Brazilian Forest Code and the specificities of the properties of the familiar agriculture in this scenario was carried out, and a case study was chosen. A family farm was selected in the municipality of Esperança do Sul, RS, which requires a permanent preservation area and has a legal reserve area greater than that required by the Forest Code. In this property was made the mapping of the area, on-site visit to observe the native forest and survey of information with the owner. Based on this information and those obtained in the documentary research, the calculation of carbon conservation and a diagnosis of the production systems based on the systemic approach were carried out. The case study pointed to the importance of a PSA in family farming properties, based on the existing conservation area, avoided carbon emissions in the case of deforestation, and the low cost in relation to a possible recovery of the area. For family farming, the PSA could stimulate the conservation of natural resources, which is a lower cost than the forest recovery.
\end{abstract}

Keywords: Payment for environmental services. Family farm. Environmental legislation. Systemic approach.

\footnotetext{
${ }^{1}$ Mestre e doutoranda em Desenvolvimento Rural pela Universidade Federal do Rio Grande do Sul (UFRGS). leticia.chechi@ufrgs.br

${ }^{2}$ Mestre em Desenvolvimento Rural pela Universidade Federal do Rio Grande do Sul (UFRGS). Pesquisadora do Núcleo de Pesquisa e Extensão em Agronegócios da Universidade Federal de Santa Maria como bolsista de Fixação de Recursos Humanos do CNPq. marieleboscardin@hotmail.com

${ }^{3}$ Mestre em Engenharia Agrícola, área de concentração de Planejamento e Desenvolvimento Rural Sustentável, pela Universidade Estadual de Campinas (Unicamp). Estudante de Doutorado pelo Programa de Desenvolvimento Rural pela Universidade Federal do Rio Grande do Sul (UFRGS). aluisamt@gmail.com
} 
O desmatamento no Brasil é uma questão histórica, desde a exploração extrativista do período colonial até os momentos mais recentes marcados pela intensificação da produção agrícola, impulsionada pela Revolução Verde. De acordo com relatórios do Painel Intergovernamental de Mudança Climáticas (IPCC), o desmatamento na Amazônia, por exemplo, ainda apresenta níveis elevados, emitindo um imenso volume de gases de efeito estufa. Para Young et al. (2007), a emissão de gases de efeito estufa por desmatamento no Brasil representa em torno de $75 \%$ das emissões do país, e o coloca entre as cinco nações que mais emitem no mundo.

O agravamento do aquecimento global e a emergência de estudos, relatórios, eventos sobre as mudanças climáticas desde a década de 70 do século 20 e, mais acentuadamente, a partir de 1990 por meio de acordos internacionais e protocolos, fez com que leis e políticas públicas incorporassem as questões ambientais. No Brasil, contudo, algumas legislações, como o Código Florestal, apesar de existir desde a década de 30, ainda enfrenta desafios para sua prática.

No ano de 2012 o Congresso Nacional aprovou a mudança da lei, instituindo um novo texto para o Código Florestal no país, o qual alterou obrigações referente às Áreas de Proteção Permanente (APPs) e Reserva Legal ( $R L$ ) e criou instrumentos nunca antes vistos na legislação ambiental nacional, como a "novidade" do Cadastro Ambiental Rural (CAR). ${ }^{4}$ Segundo Soares Filho (2013), o Brasil tem cerca de 21 milhões de hectares de passivos ambientais para serem readequados de acordo com a nova legislação, o que custaria aproximadamente $\mathrm{R} \$ 165$ bilhões.

Nesse montante de área em passivo ambiental, há muitos agricultores familiares que precisam recuperar áreas, e outros, em menor número, que possuem uma área maior de RL e APP que a exigida pela legislação. Nesse contexto, o estabelecimento de um programa de Pagamento por Serviços Ambientais (PSA) estimularia os que precisam recuperar áreas para adequar-se à legislação, e também os que possuem área excedente, para conservá-la e evitar a emissão de gases de efeito estufa (GEE) por desmatamento.

A possibilidade de estabelecimento de uma política de PSA às áreas de conservação ambiental estabelecidas no Código Florestal está sendo discutida no Brasil, entretanto, elaborar uma metodologia para essa política é um trabalho complexo, visto que se trata de serviços ambientais e também do estabelecimento de agentes pagadores e recebedores (YOUNG; BAKKER, 2014; YOUNG et al., 2016). Em torno dessa discussão, este trabalho objetiva apresentar uma proposição de PSA para uma propriedade da agricultura familiar de Esperança do Sul-RS, com base na redução de carbono emitido e abordagem sistêmica das Unidades de Produção Agrícola (UPA), no contexto de adequação ao novo marco legal do Código Florestal brasileiro.

Neste artigo a agricultura familiar é caracterizada a partir da Lei 11.326, de 24 de julho de 2006, não possuindo área maior do que quatro módulos fiscais; utiliza, predominantemente, mão de obra familiar; tenha percentual mínimo da renda advinda de atividades de seu estabelecimento e dirija propriedade com sua família (BRASIL, 2006).

${ }^{4}$ O Cadastro Ambiental Rural existe desde 2008 como parte das políticas de meio ambiente dos Estados de Mato Grosso e Pará. 
O trabalho, além desta introdução, está estruturado em quatro seções principais: a primeira apresenta uma breve discussão sobre o Código Florestal Brasileiro, seguido pela seção que aborda o conceito e principais características do PSA e outra que apresenta sucintamente a abordagem sistêmica das UPAs. A seção seguinte explicita a metodologia de trabalho seguida neste estudo. Na sequência faz-se uma simulação do PSA em uma propriedade da agricultura familiar no município de Esperança do Sul-RS. Por fim, são apresentadas algumas considerações sobre o PSA na agricultura familiar, possibilidades e desafios dessa proposição.

\section{UMA BREVE CONTEXTUALIZAÇÃO DO CÓDIGO FLORESTAL BRASILEIRO}

O primeiro Código Ambiental, lei que define como a vegetação nativa deve ser explorada no Brasil, é de 1934, instituída pelo Decreto no 23.793. Nesse período, a cafeicultura avançava pelos morros do Vale do Paraíba, e nos Estados do Paraná e Santa Catarina a Araucaria angustifolia era fortemente explorada. Em 1965 sentiu-se a necessidade de uma atualização dessa legislação, buscando proteger os recursos naturais como um todo, não apenas as árvores e florestas. Com isso, instituiu-se a Lei no 4.771, de 15 setembro de 1965, na qual se estabeleceram as Áreas de Preservação Permanente (APPs) e Reserva Legal (RL) (AHRENS, 2005).

O novo marco legal do Código Florestal Brasileiro, instituído pela Lei no 12.651, de 25 de maio de 2012, que substituiu a Lei no 4.771/1965, trouxe um conjunto de regras sobre a conservação ambiental para as propriedades rurais brasileiras. Não se objetiva neste curto espaço apresentar e discutir os conflitos em torno desta lei até sua aprovação, mas destacar os elementos mais importantes considerando a simulação de uma política de PSA.

A responsabilidade da proteção ao meio ambiente continua sendo do proprietário rural na nova legislação, por meio de espaços protegidos, divididos entre APP e RL. De acordo com o parágrafo 20 do artigo 30 do novo Código Florestal, as APPs são áreas que devem ser mantidas intactas pelo proprietário ou possuidor do imóvel rural, em virtude de sua função natural de preservação dos recursos hídricos, da paisagem, da estabilidade geológica e biodiversidade, por facilitar o fluxo gênico de fauna e flora, proteger o solo e assegurar o bem-estar das populações humanas (BRASIL, 2012).

A RL, definida no parágrafo 30 do artigo 30 , é obrigatória em toda propriedade ou posse rural, tendo a função de assegurar o uso econômico de modo sustentável dos recursos naturais do imóvel rural, auxiliar na conservação dos processos ecológicos e promover a conservação da biodiversidade, bem como servir de abrigo para a fauna silvestre e a flora nativa. A RL é delimitada de acordo com o tamanho da propriedade rural, com percentuais diferenciados para cada região do Brasil. O Rio Grande do Sul enquadra-se nas "demais regiões do país", devendo ter uma área mínima de $20 \%$ da propriedade em RL (BRASIL, 2012).

Importante destacar que, para propriedades de agricultura familiar que possuem remanescente de vegetação nativa em percentual inferior ao estabelecido no Código, a RL será constituída com a área ocupada por vegetação nativa em 22 de julho de 2008 e são proibidas novas conversões (BRASIL, 2012). Já aquelas que possuem excedente, podem ter novas conversões autorizadas pelos órgãos ambientais estaduais. 
Uma pesquisa realizada por Santiago, Caviglia-Harris e Rezende (2018) mostrou que uma propriedade rural em Rondônia, Bioma Amazônia, mesmo localizada em uma região com altos índices de desmatamento e baixa fiscalização, está desenvolvendo planos de restauração para o cumprimento do Código Florestal. Essa predisposição teria relação positiva com a diversidade de cultivos, a presença de fontes de água e áreas de maior declividade, bem como as visitas de agentes de extensão rural.

De acordo com Soares Filho (2013), a estimativa da área que precisaria ser recuperada seguindo as regras do novo Código Florestal, para adequação das áreas de APP e RL, seria de aproximadamente 21 milhões de hectares. De acordo com os autores, o maior passivo ambiental encontra-se nos Estados do Mato Grosso, Mato Grosso do Sul, Paraná e Pará, em razão do maior desmatamento nessas regiões. O valor estimado para recuperação destas áreas é de aproximadamente $\mathrm{R} \$ 165$ bilhões, considerando valores de 2013.

A área a ser recuperada para readequação à legislação é significativa mesmo considerando as áreas rurais consolidadas, definidas na lei como área de ocupação antrópica preexistente a 22 de julho de 2008. Para os imóveis rurais, pertencentes à agricultura familiar, que possuam áreas consolidadas em APP ao longo de cursos d'água naturais, nascentes, olhos d'água, lagos e lagoas naturais, são estabelecidas faixas de recomposição, o chamado "efeito escadinha" (artigo 61) (BRASIL, 2012).

O diferencial do novo marco legal do Código Florestal está na instituição e fiscalização das áreas a serem conservadas nas propriedades, por meio da inscrição no Cadastro Ambiental Rural (CAR), e do estabelecimento do Sistema Nacional de Cadastro Ambiental Rural (Sicar), uma plataforma integradora das informações das propriedades rurais. Até o mês de dezembro de 2018 todas as propriedades rurais brasileiras deveriam estar inscritas no CAR, informando suas respectivas áreas de conservação (BRASIL, 2018).

De acordo com Young e Bakker (2014), grande parte das propriedades rurais brasileiras, das diversas escalas, têm passivos ambientais que devem ser obrigatoriamente recuperados. Nesse contexto, justifica-se a importância de discussões como a apresentada neste trabalho, sobre o PSA em relação às áreas de conservação ambiental estipuladas no Código Florestal.

Trabalho realizado por Stefanes et al. (2018) no Estado do Mato Grosso do Sul, Bioma Cerrado, a partir da análise dos dados do CAR, apontou que propriedades com mais de mil hectares tem efeitos importantes para a conservação dos recursos naturais, ao mesmo tempo que propriedades menores apresentaram elevados níveis de inconformidades em relação ao Código Florestal. Com base nos dados, os autores sugerem que incentivos socioeconômicos, considerando o tamanho da propriedade, seriam relevantes para conter o desmatamento na região em que o estudo foi realizado, assim como aumentar a conformidade com o marco legal.

\section{O PAGAMENTO POR SERVIÇOS AMBIENTAIS}

O Pagamento por Serviços Ambientais (PSA) caracteriza-se como uma transação voluntária na qual um serviço ambiental, ou um uso da terra que forneça esse serviço, é adquirido por um comprador de um provedor, desde que esse prestador de serviços 
assegure a provisão do serviço (condicionalidade) (WUNDER, 2005). Ainda, de acordo com Pagiola e Platais (2007), os serviços-alvo de programas de PSA são aqueles que fornecem benefícios indiretos, ou seja, aqueles que representam externalidade a partir da perspectiva de seus fornecedores.

Na concepção de Young et al. (2007), o princípio básico dos PSAs é o mesmo que norteia as ações da política ambiental, comando e controle. O meio ambiente fornece bens e serviços de interesse direto ou indireto do ser humano, mas que não necessariamente se revertem em benefícios financeiros aos agentes que controlam o fornecimento desses serviços. Cria-se então o que é chamado de "falha de mercado", quando a busca pela opção que garante a maior lucratividade resulta em situações socialmente piores. O que diferencia são as soluções propostas, pois ao invés de estabelecer formas diretas de regulação baseada em condutas, procura-se internalizar os custos, ou benefícios, que não são contabilizados privadamente, chamados de externalidades, de modo que os geradores primários dos danos, ou beneficiários, sejam penalizados, ou beneficiados, por tais ações.

São descritos dois tipos básicos de programas de PSA (PAGIOLA; PLATAIS, 2007; ENGEL; PAGIOLA; WUNDER, 2008): um em que os prestadores de serviço são pagos pelos usuários dos serviços e, outro, em que os prestadores de serviços são pagos por um terceiro, como o governo. De acordo com os autores, o pagamento realizado pelos usuários é mais propenso a ser eficiente e, por isso, preferidos, enquanto que os programas de PSA financiados pelo governo são influenciados por pressões que são alheias aos objetivos do programa.

Um desafio para o PSA é a valoração dos serviços ambientais. De acordo com Mattos e Hercowitz (2011), há compreensão e divergências das propostas com dois tipos de valoração: direta e indireta. Para os autores, a valoração direta de serviços ambientais vem da economia ambiental e apoia-se em mecanismos como: a) disposição a pagar; b) direito de propriedade (Teorema de Coase) e c) taxas pigouvianas. Já a valoração indireta origina-se da economia ecológica e busca associar valores culturais e sociais à racionalidade econômica, o que demanda profundas mudanças institucionais, novos instrumentos econômicos e inovadoras metodologias de valoração indireta de serviços ambientais a partir de noções não monetárias (MATTOS; HERCOWITZ, 2011).

De acordo com a Avaliação Ecossistêmica do Milênio (2005), há diferentes tipos de serviços ambientais, divididos em quatro categorias, a saber: serviços de provisão, serviços reguladores, serviços culturais e serviços de suporte. Os serviços de provisão são aqueles relacionados à capacidade dos ecossistemas em prover bens, sejam eles alimentos, matéria-prima para a geração de energia, fibras, plantas ornamentais, recursos genéticos. Os reguladores são serviços obtidos a partir de processos naturais que regulam as condições ambientais que sustentam a vida humana, como a purificação do ar, regulação do clima, purificação e regulação dos ciclos das águas, entre outros. Os serviços culturais são benefícios recreacionais, educacionais, estéticos, espirituais, relacionados aos ecossistemas. Por fim, os serviços de suporte são processos naturais para que os outros serviços existam, como a ciclagem de nutrientes, polinização e dispersão de sementes. 
As florestas têm importante papel na manutenção de serviços ambientais, pela conservação da biodiversidade, armazenamento e sequestro de carbono, serviços hidrológicos, beleza cênica e serviços culturais. No Brasil os instrumentos utilizados para garantir os serviços ambientais prestados pelas florestas e ambientes naturais preservados são os coercitivos, como as multas, baseadas no princípio "poluidor pagador", amparado pela legislação ambiental, como na Lei de Crimes Ambientais no 9.605/1998. Estudos, no entanto, têm demonstrado que a utilização de políticas de incentivo, baseadas no princípio do "provedor-recebedor", podem ser mais eficazes (CLAASSEN et al., 2001). Programas que utilizam o PSA são considerados pela FAO (2004) como mecanismos promissores para a proteção e restauração ambiental e também como forma de complementar e reforçar regulações existentes.

Nos serviços ambientais relacionados à conservação florestal, um sistema de PSA pode ser estabelecido onde os que se beneficiam por tais serviços realizam pagamentos para o proprietário ou gestor da área em questão, garantindo o fluxo contínuo e a meIhoria do serviço demandado. Os pagamentos podem ser vistos como uma fonte adicional de renda, para ressarcir as práticas conservacionistas que permitem o fornecimento dos serviços ambientais. Trata-se do princípio do "provedor-recebedor", quando o usuário paga e o que está conservando recebe (PAGIOLA; LANDEL-MILLS; BISHOP, 2005).

O uso de PSA tem se difundido na América Latina, principalmente após a criação do "Programa de Pagos por Servicios Ambientales (PPSA)" na Costa Rica, em 1997. A iniciativa da Costa Rica levou outros países e outros atores envolvidos na gestão de recursos ambientais a considerar o PSA. Com isso, até o ano de 2009, havia mais de 150 programas de PSA e similares em operação na América Latina, conservando cerca de 2,5 milhões de hectares (CAMHI; PAGIOLA, 2009).

Programas de PSA voltados, principalmente, a serviços locais de água têm sido a forma mais comum no Brasil e na América Latina (CAMHI; PAGIOLA, 2009). No Brasil, os primeiros programas de PSA foram instituídos no ano de 2006 em Minas Gerais, nos municípios de Extrema e Montes Claros, e a partir desses, diversos programas foram desenvolvidos: em Apucarana, no Paraná; Rio Claro, no Rio de Janeiro; Campo Grande, no Mato Grosso do Sul, entre outros. Programas centrados em carbono também são registrados no Brasil, com os primeiros sendo financiados por agentes externos, pelo Prototype Carbon Fund (PCF) do Banco Mundial, no caso do Projeto Pro Natura em Mato Grosso, e pela Companhia American Eletric Power, no Projeto Ação Contra o Aquecimento Global em Guaraqueçaba, no Paraná. Já o Programa Carbono Seguro, em São Paulo, e Corredor Ecológico Monte Pascoal-Pau-Brasil, na Bahia, são, por exemplo, projetos financiados localmente, orientados para o mercado voluntário nacional, desenvolvidos por Organizações Não Governamentais (ONGs) (PAGIOLA; VON GLEHN; TAFARELLO, 2013).

De acordo com Queiroz (2008), os programas de PSA também ganharam força no Brasil após a publicação do "Pacto pela Valorização da Floresta e pelo fim do Desmatamento na Amazônia", em 2007, mais conhecido como "Desmatamento Zero" (YOUNG et al., 2007). O documento do "Desmatamento Zero" argumenta que a eficiência e eficácia esperada das políticas públicas para contenção do desmatamento, além das ações de comando e controle, dependem da revisão dos incentivos financeiros, historicamente canalizados para atividades predatórias (YOUNG et al., 2007). 
No PSA, inicialmente é necessária a identificação de que, ao menos, um serviço ambiental esteja beneficiando algum agente interessado em garantir a manutenção de tal serviço, disponibilizando-se a pagar por ele, de forma voluntária ou pela criação de mecanismos que imponham o pagamento. A parte recebedora deve ter capacidade de garantir a preservação da floresta. Para isso há necessidade de sistemas de monitoramento eficazes que garantam os efeitos ambientais, sociais e econômicos dos PSAs. Como os serviços ambientais não possuem preço de mercado, o valor pode ser dimensionado mediante diferentes técnicas de valoração de serviços ambientais, contudo não se deve esperar que PSAs sejam soluções universais (YOUNG et al., 2007).

Dois elementos estão sempre presentes nas experiências bem-sucedidas de PSAs: a gravidade do problema ambiental faz com que a sociedade aceite a cobrança por algum tipo de instrumento, como usuário-poluidor, servindo de base para o pagamento de serviço ambiental; políticas públicas são estabelecidas para viabilizar o sistema. De acordo com Young et al. (2007), várias propostas de PSAs para a conservação florestal acabaram não saindo do estágio experimental porque esses elementos não foram consolidados.

O trabalho realizado por Young (2016) destaca a dificuldade de precificação de recursos ambientais e a complexidade da proposição do PSA como política governamental, visto que isso impacta em grupos de agentes pagadores e recebedores. Buscando atenuar a complexidade, os autores propõem no seu estudo modelos de quantificação de serviços ambientais vis-à-vis ao custo de oportunidade da terra e dos recursos naturais.

O custo de oportunidade da terra corresponde ao valor sacrificado (em termos monetários) pela não utilização das terras em atividades agropecuárias em razão da sua conservação. Trata-se da renda mínima que o proprietário rural está disposto a receber para conservação das áreas protegidas ou regenerar vegetação nativa em sua propriedade (YOUNG; BAKKER, 2014). De acordo com Young (2016), se a transferência de recursos aos proprietários da terra for pelo menos igual ao custo de oportunidade, do ponto de vista do interesse privado, seria indiferente para o agente conservar as áreas ou convertê-las para o uso agropecuário. Dessa forma, são os ganhos de bem-estar coletivo em razão da manutenção dos bens e serviços ambientais que justificam a adoção de um programa de PSA.

Tratando-se da agricultura familiar, a complexidade desse cálculo aumenta, pois é preciso considerar além do aspecto econômico, dimensões sociais, ambientais e culturais, o que não está contemplado no custo de oportunidade proposto por Young (2016). Nesse contexto, a metodologia que mais se aproxima dessa realidade está presente na abordagem sistêmica das Unidades de Produção Agrícola. Ampliando essa complexidade, os agricultores podem estabelecer uma relação intangível com a mata nativa, o que não pode ser dimensionado, nem quantificado em relação a valores monetários. Mesmo assim, políticas de incentivo para conservação desses espaços devem ser discutidas.

A conservação ambiental resultante de um programa de PSA poderia gerar benefícios ambientais como redução das emissões de GEE por desmatamento. O potencial de redução de emissão de carbono por conservação florestal refere-se, principalmen- 
te, ao dióxido de carbono $\left(\mathrm{CO}_{2}\right)$ (YOUNG, 2016). Esse componente é também conhecido na literatura como Reducing Emissions from Deforestation and Forest Degradation (REDD). ${ }^{5}$

O REDD pode ser caracterizado como um mecanismo para beneficiar quem evita a emissão de carbono, apontado como uma importante alternativa para reduzir as emissões oriundas de desmatamento (SANTILLI et al., 2005). A questão de como instituir um conjunto de políticas e incentivos para redução das emissões provenientes de desmatamento e degradação florestal, um mecanismo global de REDD, tornou-se o tema chave da 13ạ Conferência das Partes da Convenção das Nações Unidas sobre Mudanças Climáticas (UNFCCC), realizada em Bali em 2007.

Um estudo do Ministério do Meio Ambiente (MMA) identificou a conservação florestal como um instrumento para o estabelecimento de incentivos e políticas para redução do desmatamento e degradação florestal. Esta é considerada uma das formas mais rápidas e baratas para redução das emissões de carbono em grande escala (MMA, 2012).

Diante desse contexto, na próxima seção busca-se apresentar as características da abordagem sistêmica das Unidades de Produção Agrícola (UPAs), contemplando, além da dimensão econômica, as dimensões sociais e ambientais, como alternativa na construção de um PSA. Considerando que este estudo de caso tem como base uma propriedade da agricultura familiar, faz-se necessária uma metodologia que contemple outros elementos para além do econômico, presente no custo de oportunidade da terra.

\section{A ABORDAGEM SISTÊMICA DAS UNIDADES DE PRODUÇÃO AGRÍCOLA}

As Unidades de Produção Agrícolas (UPAs) são formatadas pelos agricultores e produtores rurais, que organizam suas atividades produtivas a partir de suas condições materiais e de seu legado cultural, étnico e social (WAGNER et al., 2010). Deste modo, Miguel e Mazoyer (2014) destacam que, ao analisar as UPAs é importante não apenas uma análise dos fatores de produção diretamente envolvidos com a produção agropecuária, mas também uma aproximação com a questão social. Nesse contexto, a compreensão da estrutura e do funcionamento das UPAs e das particularidades que caracterizam os agentes diretamente envolvidos nesse processo refere-se a uma condição fundamental e indispensável para a realização de ações de planejamento e de gestão nas Unidades de Produção Agrícola.

De acordo com Miguel (2010), a abordagem sistêmica refere-se a uma ferramenta de análise, a qual constitui o arcabouço científico fundamental para a compreensão e a análise do funcionamento das Unidades de Produção Agrícola. Busca-se, com esta abordagem, resgatar e compreender a diversidade e as inter-relações entre os elementos constitutivos de um objeto e o ambiente externo.

A referida abordagem emerge como alternativa à abordagem setorial e segmentada que privilegiava a desconstrução e o estudo isolado dos elementos e partes constitutivas das Unidades de Produção Agrícola, aceitando como verdade que o conhecimento isolado das partes permitia a compreensão da UPA em sua totalidade. Além da segmentação do conhecimento, a abordagem setorial reduzia consideravelmente a importância

5 Redução das Emissões por Desmatamento e Degradação Florestal (tradução). 
e a influência do homem na gestão e condução das UPAs. O agricultor ou produtor rural era, portanto, considerado um mero executor de medidas e ações predeterminadas, impostas por agentes externos (MIGUEL, 2010).

De acordo com o mesmo autor, incorpora-se com a abordagem sistêmica a noção de que a UPA pode apresentar, além da função de produção agrícola, outras funções combinadas, tais como de comercialização, serviços, conservação do meio ambiente, entre outras. Além disso, o agricultor ou produtor rural passa a ser valorizado e considerado como protagonista da UPA.

Assim, Miguel e Mazoyer (2014) ressaltam que a Unidade de Produção Agrícola pode ser concebida como um sistema composto de um conjunto de elementos em interação (sistemas de cultivo e/ou criação e/ou transformação), influenciado pelos objetivos do agricultor ou produtor rural e de sua família que correspondem ao sistema social em interação com o meio externo (econômico, físico e humano).

Os objetivos do agricultor e de sua família ocupam uma posição central no processo de tomadas de decisão, portanto, para a compreensão dos mecanismos de funcionamento e gestão de uma UPA, é importante conhecer o comportamento do agricultor.

\section{METODOLOGIA}

Na pesquisa qualitativa a pressuposição básica é de que a realidade é constituída de fenômenos construídos e o objetivo é compreender melhor esses fenômenos. Na pesquisa quantitativa exploram-se dados numéricos, buscando identificar e classificar relações entre variáveis e possibilitar maior margem de inferências (RICHARDSON, 2009; APPOLINÁRIO, 2011). Com isso, o uso de métodos de pesquisa qualitativo e quantitativo, de forma complementar, resulta no chamado método misto, buscando a convergência de dados e obtendo uma análise mais ampla do problema (CRESWELL, 2010).

Esse estudo utiliza-se do método misto de pesquisa, buscando dados qualitativos e quantitativos sobre a propriedade rural por meio da abordagem sistêmica da UPA e a metodologia de redução de carbono emitido. A pesquisa é caracterizada como de natureza aplicada, ou seja, objetivou o incremento científico sobre um problema específico, de realidade local, com relevância teórica (APPOLINÁRIO, 2011). Para tanto, inicialmente foi realizada uma análise documental, recorrendo-se a fontes diversas, como relatórios, documentos oficiais, artigos, entre outros. Em seguida procedeu-se ao estudo de caso, uma pesquisa em que se focaliza em uma unidade, uma entidade bem definida, nesse caso uma propriedade da agricultura familiar, buscando conhecer em profundidade como e por que de determinados aspectos e discutir uma proposição de PSA no contexto de adequação ao marco legal do Código Florestal Brasileiro (FONSECA, 2002).

O estudo de caso teve como base uma propriedade localizada no distrito de Linha Lara, município de Esperança do Sul, Região Noroeste do Estado do Rio Grande do Sul (Figura 1), município de 3.272 habitantes, cujas principais atividades econômicas são procedentes da agricultura (soja, milho, trigo, fumo), suinocultura, produção de leite e derivados, desenvolvidas em propriedades de agricultura familiar (IBGE, 2006, 2010). A escolha da propriedade deu-se por apresentar característica de interesse para o objeto do estudo de PSA em propriedades da agricultura familiar, a saber: área de mata nativa superior ao exigido como Reserva Legal pelo Código Florestal, de acordo com a região onde está localizada - 20\% da área total do imóvel (BRASIL, 2012). 
Figura 1 - Representação da localização do município de Esperança do Sul-RS

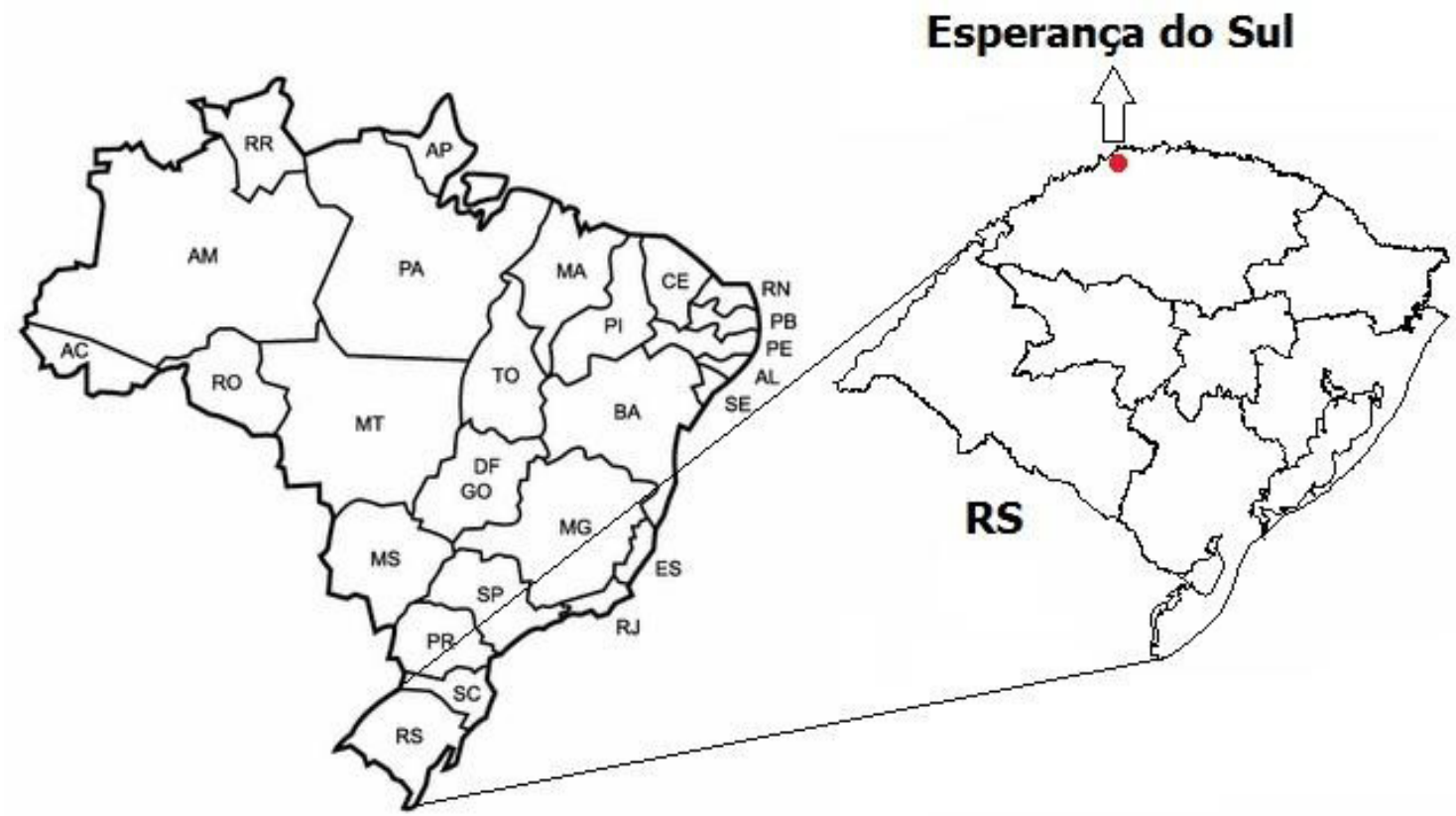

Fonte: Elaborada pelas autoras (2017).

Após a escolha da propriedade, o primeiro procedimento foi a delimitação da área do imóvel por intermédio do Google Earth Pro, com imagens de 16/04/2016 (Figura 2). Após delimitação da área de interesse, o arquivo $\mathrm{Kml}$ foi processado no programa Qgis, para geração de mapa temático, com a delimitação da área agrícola, reflorestamento com espécie exótica, área de mata nativa, vias de acesso e rio. Após a geração do mapa foi realizada uma visita in loco para confirmação das áreas delimitadas na imagem de satélite, mediante observação direta e também pelo conhecimento do proprietário sobre a área. Nessa etapa da pesquisa também foi realizada uma entrevista com o proprietário utilizando um roteiro semiestruturado, visando a contemplar as questões do diagnóstico do sistema de produção, por meio da abordagem sistêmica de UPA e perguntas abertas sobre a percepção do agricultor em relação à preservação de mata nativa e a possibilidade de um PSA.

Posteriormente, realizou-se uma análise do diagnóstico do sistema de produção, esta feita com base na abordagem sistêmica de UPA. Para maior detalhamento foi necessário o cálculo de algumas medidas ou indicadores de desempenho agronômico. Os principais indicadores que fizeram parte desse estudo referem-se a Superfície Agrícola Útil (SAU); Unidade de Trabalho Homem (UTH); Produção Bruta (PB); Valor Agregado Líquido (VAL) e Renda Total (RT).

Em relação ao valor mínimo do carbono para o PSA foi realizada inicialmente uma pesquisa sobre a densidade de carbono acima do solo, para então calcular a redução de carbono emitido e chegar ao seu valor. Esse cálculo possibilitará chegar ao valor mínimo que estimularia o proprietário a manter a floresta em pé, no caso de instituição de PSA por créditos de carbono baseadas no REDD. A equação 1 demonstra os detalhes do cálculo. 
Figura 2 - Delimitação da propriedade no Google Earth Pro

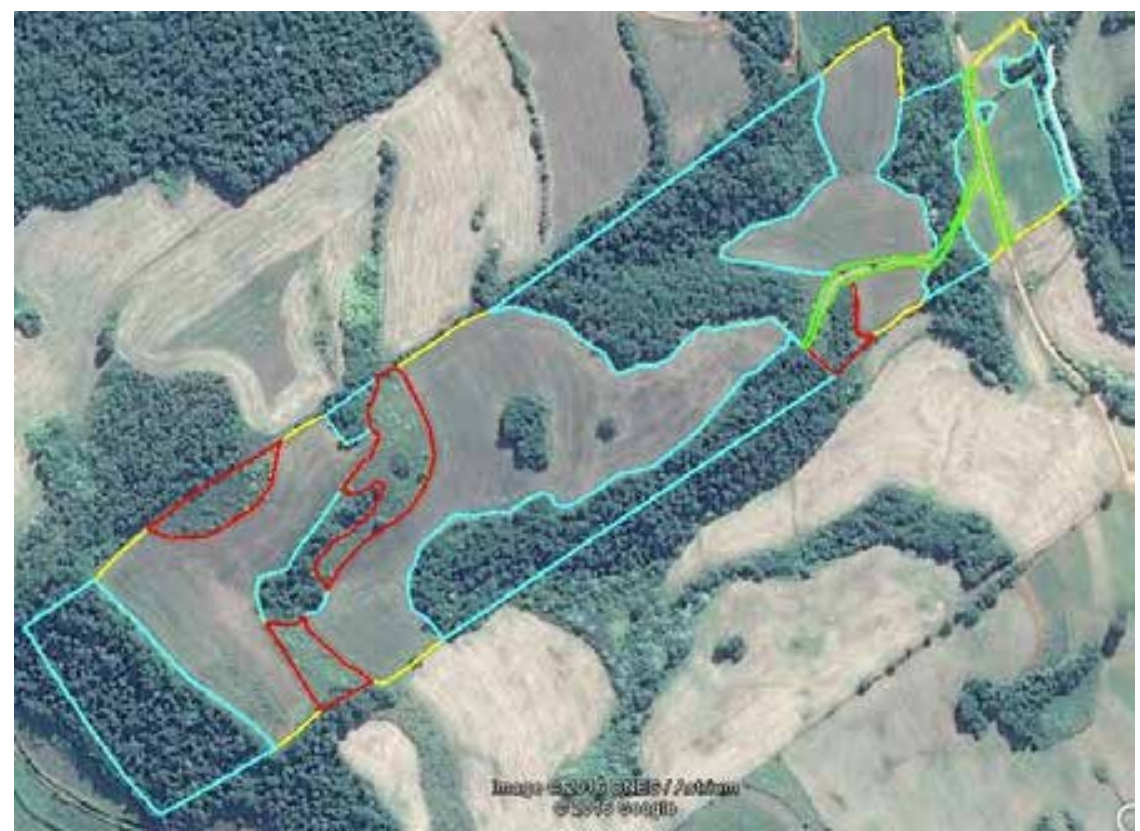

Fonte: Google Earth Pro (2016).

Equação 1.

$$
E=D \times A
$$

onde $\mathrm{E}$ é a redução de carbono emitido por conservação florestal (toneladas de carbono); D corresponde à densidade de carbono acima do solo - em toneladas de carbono/ hectare (MCT, 2010); e A refere-se à área a ser conservada dado o estabelecimento de um PSA (hectares). A propriedade rural em questão está localizada em Floresta Ombrófila Mista alto montana ( $\mathrm{Mm})$, que de acordo com o "Segundo inventário brasileiro de emissões e remoções antrópicas de gases de efeito estufa" tem um estoque médio de carbono de 118,81 tC/ha (MCT, 2010, p. 67).

Com o diagnóstico do sistema de produção, a partir da abordagem sistêmica, o Valor Agregado Líquido (VAL) dividido pela Superfície Agrícola Útil (SAU), resultou no VAL por hectare, dado que foi utilizado para o cálculo da estimativa do preço da tonelada de carbono em uma simulação de PSA. Esse cálculo foi realizado por meio da divisão do VAL/ha por $118,81 \mathrm{tC} /$ ha, considerado estoque médio de carbono na região na qual a propriedade está localizada, resultando no valor mínimo da tonelada de carbono que tornaria viável uma política de PSA no caso dessa propriedade da agricultura familiar. Ainda, como alternativas na proposição de um PSA, utilizou-se o valor de arrendamento da região, declarado pelo agricultor familiar, e o valor que ele consideraria justo pela conservação da área de mata nativa.

\section{SIMULAÇÃO DO PAGAMENTO POR SERVIÇOS AMBIENTAIS (PSA) EM UMA PROPRIEDADE FAMILIAR}

A propriedade rural, objeto deste estudo, possui uma área de 22 hectares, distribuídos entre área agrícola (11 hectares), mata nativa (9,4 hectares), reflorestamento com eucalipto ( 1,3 hectares) e vias de acesso - 0,35 hectare (Figura 3 ). De acordo com o Código Florestal (artigo 12), essa propriedade deve ter, no mínimo, 4,4 hectares de 
reserva legal, o que corresponde a $20 \%$ da sua área total. No momento ela possui mais de $40 \%$ da sua área coberta com mata nativa, o que justifica a importância da discussão de alternativas de PSA.

Figura 3 - Delimitação da área de estudo

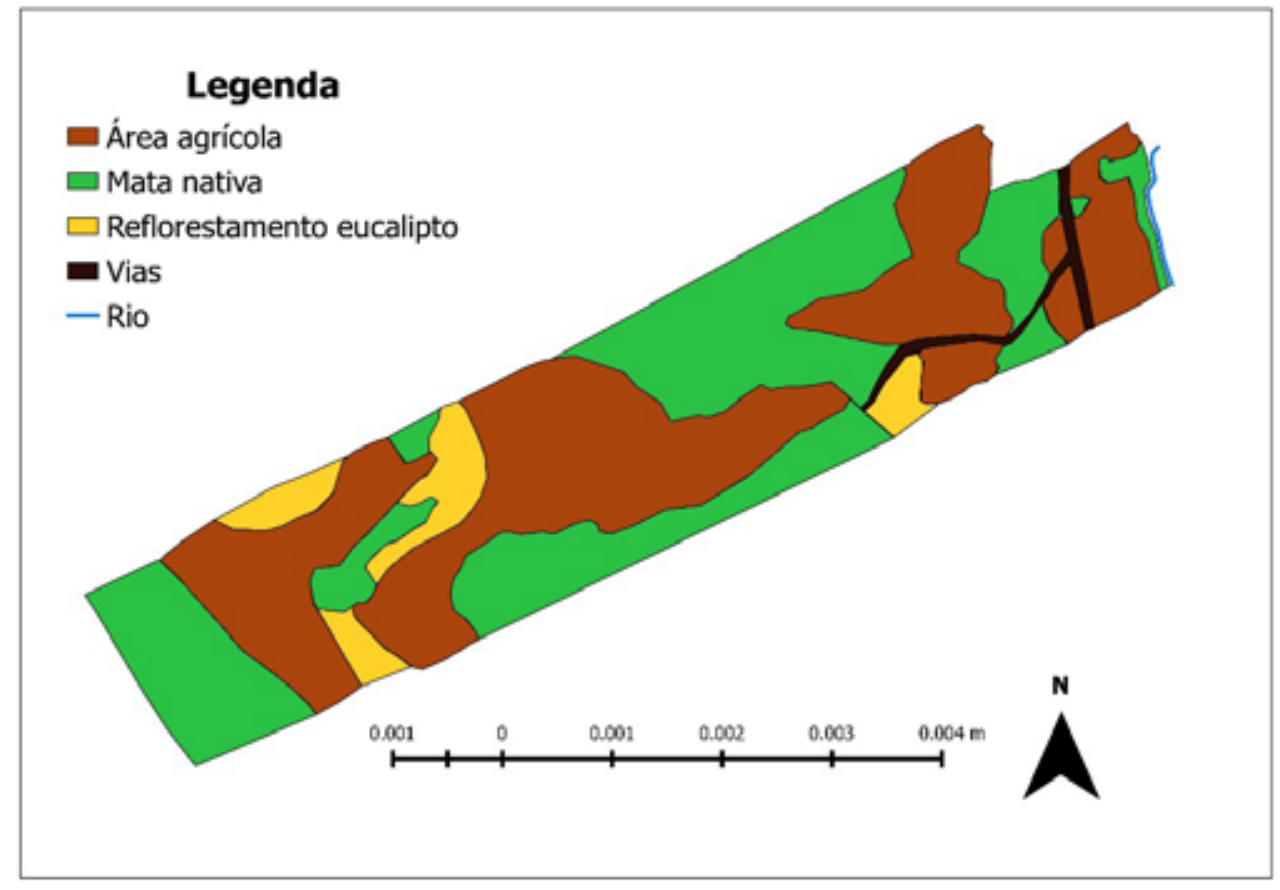

Fonte: Elaborada pelas autoras (2017).

De posse da propriedade há mais de dez anos, quando perguntado sobre o porquê de não haver feito a conversão de uso das áreas de mata nativa, o proprietário explica primeiramente que há dificuldade de obtenção de licenças, devido à existência de espécies imunes ao corte na área, como grápia (Apuleia leiocarpa), figueiras (Ficus sp.) e umbu (Phytolacca dioica). Em um segundo momento ele menciona que se trata de áreas de terreno rochoso, e algumas com maior declividade, o que tornaria necessário um investimento inicial e haveria dificuldades de desenvolvimento de culturas anuais.

Em relação à adequação ao novo marco legal do Código Florestal, como já mencionado, a área de RL exigida está adequada. Em relação à APP, uma das áreas de mata nativa da propriedade abriga uma nascente, e os 50 metros de raio mínimo são respeitados. Uma segunda área de APP presente na propriedade deve-se ao Rio Lara, que delimita uma das divisas da propriedade, tendo este menos de 5 metros de largura. A escala da imagem de satélite não permite a visualização, mas com a observação direta foi possível observar o plantio de árvores na área de APP. O proprietário explica que anteriormente ao contrato de arrendamento, essa área era de gramíneas, sem vegetação, que corresponderia à área de APP. Com o arrendamento, ela foi explorada com cultura agrícola, mas o proprietário explica que está recuperando a faixa de cinco metros exigida na nova legislação, com a introdução de mudas nativas.

De acordo com Young (2016), os custos de recuperação florestal, considerando cercamento do terreno e espécies florestais diversas é em média $\mathrm{R} \$ 7.770 /$ ha. Esse valor não inclui transporte, taxas de administração e a introdução de espécies nativas. 
Mesmo sem a inclusão de mudas nativas, considerando esse valor como base para recuperação da faixa de APP da área de estudo, o proprietário gastaria aproximadamente $\mathrm{R} \$ 1.165,50$.

Atualmente a propriedade está preservando em RL, mais do que é exigido no Código Florestal. Nesse sentido, o PSA dessa área seria um estímulo ao produtor para não desmatar, consequentemente, não emitir gases de efeito estufa, contribuindo para a redução das taxas brasileiras como acordado internacionalmente. A precificação dos serviços ambientais, no entanto, é uma tarefa complexa, pois a elaboração de uma metodologia geral e ampla pode não contemplar a especificidade das regiões e propriedades.

Considerando a complexidade de proposição de um PSA, e as especificidades de pequenas propriedades rurais brasileiras, neste estudo de caso foram calculados alguns indicadores de desempenho agronômico que fazem parte a abordagem sistêmica das UPAs. Alguns dos indicadores trabalhados foram: a) Superfície Agrícola Útil (SAU), que mensura a área em hectares, ocupada pelas atividades agrícolas de produção animal e vegetal que é efetivamente cultivada pelo agricultor. Não são consideradas como SAU as áreas de preservação e não cultivadas; b) Unidade de Trabalho Homem (UTH), que trata da quantidade de tempo trabalhada por unidade de mão de obra; c) Produto Bruto (PB), que corresponde ao valor final dos produtos agrícolas e beneficiados gerados no decorrer do ano agrícola na Unidade de Produção Agrícola, e d) Valor Agregado Líquido (VAL): o Valor Agregado mede a riqueza em reais produzida na propriedade, demonstrando a eficiência econômica da unidade de produção. Integra o PB a produção vendida, a produção consumida pela família e a produção estocada. Esses indicadores, para a propriedade rural em questão, podem ser observados na Tabela 1.

Tabela 1 - Indicadores de desempenho agronômico anual da UPA em Esperança do Sul-RS

\begin{tabular}{lc}
\hline INDICADOR & VALOR (R\$) \\
\hline Superfície Total (ST) & 22,0 \\
Superfície Agrícola Útil (UTH) & 12,3 \\
Produto Bruto (PB) & $36.384,50$ \\
Valor Agregado Líquido (VAL) & $36.176,17$ \\
Renda Total (RT) & $52.163,35$ \\
\hline
\end{tabular}

Fonte: Elaborada pelas autoras (2017).

A análise dos estratos de Superfície Agrícola Útil (SAU) demonstra que o agricultor dispõe de pequeno estrato de área agricultável, o qual é representado por 12,3 hectares. A Mão de Obra Utilizada Total (UTH), utilizada na referida propriedade, é de 0,38, destacando-se que predomina a mão de obra familiar, representada por 0,25 UTH.

O Produto Bruto (PB), ou seja, o valor final dos produtos agrícolas corresponde a $\mathrm{R} \$ 36.384,50$. Em relação à Renda Total do produtor rural, esta é igual a $\mathrm{R} \$ 52.163,35$, predominando os ingressos monetários oriundos de rendas não agrícolas, provenientes de ocupações no meio urbano, representado por $\mathrm{R} \$ 33.600,00$. As rendas agrícolas são representadas pelo cultivo de milho e soja. 
Na propriedade em questão, a PB e o VAL representam respectivamente, $R \$$ $36.384,50$ e $\mathrm{R} \$ 36.176,17$. Analisando o VAL relacionado com a Superfície Agrícola Útil (SAU), o qual representa a produtividade da terra, tem-se o valor de $\mathrm{R} \$ 2.941,15$ por hectare de terra agricultável útil. Como apresentado por Young (2016), uma metodologia de proposição de PSA é pela conservação do carbono. Como já especificado anteriormente, o estoque médio, de acordo com a localização da propriedade, é de 118,81 tC/ha, o que representa 1.116,81 tC nos 9,4 hectares de área preservada que a propriedade apresenta.

Com as informações referente às emissões que seriam evitadas com o VAL por unidade de área útil familiar, é possível calcular o preço da tonelada de carbono que cobriria os custos de oportunidade da terra e induziriam à conservação da mata nativa na propriedade. Os resultados mostram que o valor mínimo da tonelada de carbono que tornaria viável uma política de PSA seria de R\$24,75. De acordo com Young et al. (2007) e Young (2016), valores encontrados nesse tipo de proposição são variáveis na literatura.

Quando questionado o proprietário sobre um possível PSA na área de mata nativa existente na propriedade, RL e APP, ele acredita ser um incentivo importante ao agricultor. De acordo com o entrevistado, a área de mata é visualizada ainda como um "problema" nas propriedades, por não serem apresentadas atividades alternativas de rendimento econômico. É, entretanto, da importância dessas áreas, e considera que o PSA destas estimularia os agricultores a trabalharem melhor, pensando em produtividade por hectare nas áreas agrícolas já existentes, preservando as áreas naturais.

Referente ao valor por hectare a ser recebido anualmente, o proprietário menciona que qualquer valor recebido já seria interessante, visto que atualmente não há nenhum tipo de rendimento econômico da área. Acredita, contudo, que as áreas naturais devem ser valorizadas, por isso cita um valor de $\mathrm{R} \$ 1.000,00$ por hectare anual. Este pagamento poderia ser realizado por meio de dois tipos básicos de programas, um em que os prestadores de serviço são pagos pelos usuários dos serviços e outro em que os prestadores de serviço são remunerados por um terceiro, como o governo. De acordo com Young et al. (2007), políticas públicas devem ser estabelecidas para viabilizar o sistema.

Considerando os resultados obtidos nesse estudo de caso, a Tabela 2 apresenta uma síntese dos valores dos indicadores agronômicos obtidos pela abordagem sistêmica e conservação do carbono para a área total conservada na propriedade, que é de 9,4 hectares. Também apresenta os valores de arrendamento da região declarados pelo agricultor, bem como o valor que ele consideraria um estímulo interessante para conservar a mata nativa na propriedade.

Tabela 2 - Síntese dos resultados de custo de oportunidade da terra e conservação do carbono

\begin{tabular}{|l|c|c|}
\hline Custo de oportunidade da terra & $\mathbf{R} \mathbf{\$} / \mathbf{h a / a n o}$ & Total para mata conservada (9,4 ha/ano) \\
\hline Conservação do carbono (tC/ha)* & $2.940,50$ & $27.641,14$ \\
\hline Arrendamento & 943,80 & $8.871,72$ \\
\hline Declarado pelo agricultor familiar & $1.000,00$ & $9.400,00$ \\
\hline
\end{tabular}

* $118,81 \mathrm{tC} /$ ha e valor da $\mathrm{tC}=\mathrm{R} \$ 24,75$.

Fonte: Elaborada pelas autoras (2017). 
A Tabela 2 mostra que, no caso da instalação de uma PSA com as metodologias propostas, o valor poderia variar de $\mathrm{R} \$ 943,00$ a $\mathrm{R} \$ 2.940,00$ por hectare. Considerando a área total de mata nativa preservada na propriedade, esse valor variaria de $\mathrm{R} \$$ $8.871,72$ a $\mathrm{R} \$ 27.641,14$ anuais. Considerando que os custos de recuperação florestal são em média R\$7.770,00/ha, de acordo com Young (2016), essa proposição de PSA apresenta valores relativamente inferiores, sendo então uma importante alternativa para a conservação florestal no Brasil.

Tendo em conta a informação do proprietário referente às condições de solo e topografia da área de mata nativa da propriedade, infere-se que o seu custo, em uma preposição de PSA, deve ser inferior ao da área agrícola. Igualmente deve-se destacar que no caso de execução de um programa de PSA, o produtor, provavelmente, não receberia o valor total apresentado pelos indicadores da abordagem sistêmica como compensação pela conservação florestal.

Young e Bakker (2014), na metodologia de cálculo do valor a ser pago ao proprietário rural em uma proposta de política de instituição do PSA, sugerem estabelecer um percentual do custo de oportunidade da terra mais baixo na região, por hectare de floresta conservada. Esse critério também foi pensado para este estudo de caso, considerando $25 \%$ do resultado do indicador agronômico VAL/SAU. Neste sentido, a Tabela 3 apresenta essa simulação, considerando $25 \%$ dos valores já apresentados para essa propriedade.

Tabela 3 - Simulação do PSA considerando $25 \%$ do VAL/SAU e conservação do carbono calculado

\begin{tabular}{|l|c|c|}
\hline Custo de oportunidade da terra & $\mathbf{R} \mathbf{\$} / \mathbf{h a / a n o}$ & Total para mata conservada (9,4 ha/ano) \\
\hline Conservação do carbono (tC/ha)* & 735,12 & $6.910,28$ \\
\hline Arrendamento & 235,95 & $2.217,93$ \\
\hline Declarado pelo agricultor familiar & 250,00 & $2.350,00$ \\
\hline
\end{tabular}

* 118,81 tC/ha e valor da tC $=\mathrm{R} \$ 24,75$.

Fonte: Elaborado pelas autoras (2017).

Como pode ser observado na Tabela 3, os valores de um possível PSA, que podem ser considerados baixos em relação ao custo de recuperação florestal, são ainda inferiores considerando a metodologia proposta, de diagnóstico de sistemas de produção e de redução do carbono emitido. Nesse caso, os valores variam de $\mathrm{R} \$ \mathrm{R} \$ 235,95$ a $\mathrm{R} \$ 735,12$ anuais por hectare, enquanto para a área total de mata nativa da propriedade esse valor iria de $\mathrm{R} \$ 2.217,93$ a $\mathrm{R} \$ \mathbf{6 . 9 1 0 , 2 8}$ anuais. No tocante à área total da mata nativa, $\mathrm{O}$ valor pode ser aumentado, de acordo com Young e Bakker (2014), em razão da qualidade da conservação ambiental e das práticas agropecuárias adotadas.

\section{CONSIDERAÇÕES FINAIS}

A partir deste estudo de caso é possível observar que o PSA é uma importante alternativa para estímulo à conservação florestal, redução do desmatamento e, consequentemente, redução da emissão de gases de efeito estufa. Como foi possível observar, o PSA seria uma política ambiental vantajosa também no aspecto econômico, haja vista que seu valor mais elevado seria de $\mathrm{R} \$ 2.940,00 /$ hectare no caso estudado, 
enquanto os custos de recuperação florestal são em média $R \$ 7.770,00 /$ ha. Além disso, este instrumento poderia estimular os produtores rurais que possuem passivos ambientais a serem regularizados a readequarem suas áreas.

Além das reduções e do cumprimento dos acordos climáticos assinados pelo Brasil, uma política de PSA poderá ser um grande estímulo para valorização das florestas e recursos naturais. Com o avanço dos estudos, já não é mais aceitável a justificativa do desmatamento para produção de alimentos, para o desenvolvimento do país, e políticas que estimulem à conservação ambiental reforçam a ideia de que um redirecionamento é possível em benefício de todos.

Em relação às propriedades da agricultura familiar, como o objeto deste estudo de caso, muitas foram as políticas desenvolvidas para o estímulo à produção agrícola ao longo do tempo, o que, de certa forma, acabava incentivando os agricultores a derrubarem as florestas nativas, aterrar banhados, entre outras práticas. Atualmente, com a emergência das questões ambientais, é preciso conservar os recursos naturais, e políticas de incentivo são importantes nesse processo.

A complexidade da proposição de um PSA aumenta quando se trata de pequenas propriedades, pois além da dimensão econômica, é preciso considerar as dimensões sociais, ambientais e culturais presentes, inclusive levando em conta a questão da relação que os agricultores podem manter com a mata nativa, uma dimensão intangível e não mensurável. Mesmo assim, para preservação dessas áreas, políticas de incentivo para conservação desses espaços devem ser discutidas. Como é possível observar nos resultados apresentados, as metodologias de PSA são condizentes com a realidade, ou seja, podem ser postas em prática.

É importante salientar que este trabalho possui limitações, pois trata-se de um estudo de caso, de uma pequena propriedade rural, localizada em uma região específica, portanto os resultados só podem ser extrapolados se feitas as adaptações às peculiaridades de cada região. Na continuidade de estudos sobre PSA em propriedades rurais no Brasil cabem reflexões acerca do seu funcionamento e governança.

\section{REFERÊNCIAS}

AHRENS, S. O Código Florestal Brasileiro e o uso da terra: histórico, fundamentos e perspectivas - uma síntese introdutória. Revista de Direitos Difusos, v. 6, n. 31, p. 81-102, 2005.

APPOLINÁRIO, F. Metodologia da ciência: filosofia e prática da pesquisa. São Paulo:

Cengage Learning, 2011.

BRASIL. Presidência da República. Decreto no 9.395, de 30 de maio de 2018. Prorroga o prazo de inscrição ao Cadastro Ambiental Rural - CAR. Disponível em: http://www2.camara.leg.br/legin/fed/decret/2018/ decreto-9395-30-maio-2018-786805-publicacaooriginal-155741-pe.html. Acesso em: 30 out. 2018.

BRASIL. Presidência da República. Lei no 11.326, de 24 de julho de 2006. Estabelece as diretrizes para a formulação da Política Nacional da Agricultura Familiar e Empreendimentos Familiares Rurais. Disponível em: http://www.planalto.gov.br/ccivil_03/_ato2004-2006/2006/lei/l11326.htm. Acesso em: 30 out. 2018.

BRASIL. Presidência da República. Lei no 12.651, de 25 de maio de 2012. Dispõe sobre a proteção da vegetação nativa. Disponível em: http://www.planalto.gov.br/ccivil_03/_ato2011-2014/2012/lei//12651.htm. Acesso em: 13 jan. 2017.

CAMHI, A.; PAGIOLA, S. Payment for Environmental Services mechanisms in Latin America and the Caribbean: Acompendium. Washington: World Bank, 2009. 
CLAASSEN, R. et al. Agri-Environmental Policy at the Crossroads: Guideposts on a Changin Glandscape. Usda-ERS Report n. 794, 2001. Disponível em: https://www.ers.usda.gov/webdocs/publications/ aer794/32146_aer794_002.pdf>. Acesso em: 15 jan. 2017.

CONAB. Companhia Nacional de Abastecimento. Custos de produção. Disponível em: http://www.conab. gov.br/conteudos.php?a=1546\&t=2. Acesso em: 11 jan. 2017.

CRESWELL, J. W. Projeto de pesquisa: métodos qualitativo, quantitativo e misto. 3. ed. Porto Alegre: Artmed, 2010.

EMBRAPA. Empresa Brasileira de Pesquisa Agropecuária. Características da madeira de algumas espécies de eucalipto plantadas no Brasil. Disponível em: https://www.infoteca.cnptia.embrapa.br/bitstream/ doc/297469/1/doc38.pdf. Acesso em: 11 jan. 2017.

ENGEL, S.; PAGIOLA, S.; WUNDER, S. Designing payments for environmental services in theory and practice: An overview of the issues. Ecological Economics, 65(4), p. 663-674, 2008.

FONSECA, J. J. S. Metodologia da pesquisa científica. Fortaleza: UEC, 2002.

FAO. Food and Agriculture Organization of the United Nations Payment Schemes for Environmental Services in Watersheds. Land and Water Discussion Paper 3. Roma, 2004. Disponível em: ftp://ftp.fao.org/ agl/aglw/docs/lwdp3_es.pdf. Acesso em: 15 jan. 2017.

IBGE. Instituto Brasileiro de Geografia e Estatística. Censo agropecuário, 2006. Rio de Janeiro, 2006. Disponível em: http://www.sidra.ibge.gov.br/bda/tabela/listabl.asp?z=t\&o=18\&i=P\&c=816. Acesso em: 10 jan. 2017.

IBGE. Instituto Brasileiro de Geografia e Estatística. Censo demográfico, 2010. Rio de Janeiro, 2010. Disponível em: http://cidades.ibge.gov.br/download/mapa_e_municipios.php?lang=\&uf=rs. Acesso em: 10 jan. 2017.

IBGE. Instituto Brasileiro de Geografia e Estatística. Produção da extração vegetal e da silvicultura - PEVS 2015. Rio de Janeiro, 2015a. Disponível em: https://sidra.ibge.gov.br/pesquisa/pevs/quadros/brasil/2015. Acesso em: 11 jan. 2017.

IBGE. Instituto Brasileiro de Geografia e Estatística. Produção Agrícola Municipal (PAM). Rio de Janeiro, 2015b. Disponível em: https://sidra.ibge.gov.br/pesquisa/pam/tabelas. Acesso em: 10 jan. 2017.

MATTOS, L.; HERCOWITZ, M. Economia do meio ambiente e serviços ambientais: estudo aplicado à agricultura familiar, às populações tradicionais e aos povos indígenas. Brasília: Embrapa Informação Tecnológica, 2011. 294 p.

MIGUEL, L. de A. Abordagem sistêmica da unidade de produção agrícola. In: WAGNER, S. A.; GIASSON, E.; MIGUEL, L. M.; MACHADO, J. A. D. (org.). Gestão e planejamento de unidades de produção agrícolas. Porto Alegre: Ed. da UFRGS, 2010. (Série Educação a distância). Disponível em: http://www6.ufrgs.br/ cursopgdr/downloadsSerie/DERAD015.pdf.

MIGUEL, L. de A.; MAZOYER, M. Sistemas agrários e desenvolvimento rural. In: CONTERATO, M. A.; RADOMSKY, G. F. W.; SCHNEIDER, S. (ed.). Pesquisa em desenvolvimento rural - aportes teóricos e proposições metodológicas. Porto Alegre: Editora da UFRGS, 2014. p. 297-312. Vol. 1.

MCT. Ministério da Ciência e Tecnologia. Segundo inventário brasileiro de emissões antrópicas de gases de efeito estufa. Emissões de gases de efeito estufa no Setor Uso da Terra, Mudança do Uso da Terra e Florestas. 2010. Disponível em: http://www.mct.gov.br/upd_blob/0215/215990.pdf. Acesso em: 15 jan. 2017.

MMA. Ministério do Meio Ambiente. Monitoramento do desmatamento nos biomas brasileiros por satélite. Acordo de Cooperação Técnica MMA/Ibama. Monitoramento do Bioma da Mata Atlântica - 20082009. 2012.

MOTTA, D.; da SILVA, W. F.; DINIZ, E. N. Rentabilidade na plantação do eucalipto. SIMPÓSIO DE EXCELÊNCIA EM GESTÃO E TECNOLOGIA, 7., 2010. Disponível em: http://www.aedb.br/seget/arquivos/artigos10/371_rentabilidade\%20na\%20plantacao\%20de\%20eucalipto.pdf. Acesso em: 10 jan. 2017.

PAGIOLA, S.; VON GLEHN, H. C.; TAFARELLO, D. (org.). Experiências de pagamentos por serviços ambientais no Brasil. São Paulo: Secretaria do Meio Ambiente do Estado de São Paulo. 2013. Disponível em: www. mma.gov.br/estruturas/202/_arquivos/psa_na_mata_atlantica_licoes_aprendidas_e_desafios_202.pdf. Acesso em: 16 jan. 2017.

PAGIOLA, S.; LANDEL-MILLS, N.; BISHOP, J. Mecanismos baseados no mercado para a conservação florestal e o desenvolvimento. In: PAGIOLA, S.; LANDELL-MILLS, N.; BISHOP, J. (org.). Mercados para serviços ecossistêmicos: instrumentos econômicos para conservação e desenvolvimento. Brasília: Editora Rebraf, 2005.

PAGIOLA, S.; PLATAIS, G. Payments for Environmental Services: From Theory to Practice. Washington: World Bank, 2007. 
QUEIROZ, J. M. de. Custo de oportunidade da conservação e Redução de Emissão de Carbono por Desmatamento e Degradação Florestal (REDD): um estudo de caso para a Amazônia brasileira. 2008. Monografia (Bacharelado em Economia) - UFRJ, Instituto de Economia, Rio de Janeiro, 2008.

RICHARDSON, R. J. Pesquisa social: métodos e técnicas. 3. ed. São Paulo: Atlas, 2009.

SANTIAGO, T. M. O.; CAVIGLIA-HARRIS, J.; REZENDE, J. L. P. de. Carrots, Sticks and the Brazilian Forest Code: the promising response of small landowners in the Amazon. Journal of Forest Economics, vol. 30, p. 38-51, 2018.

SANTILLI, M. et al. Tropical deforestation and the Kyoto Protocol: an editorial essay. Climatic Change, 71, 2005. p. 267-276. Disponível em: http://edfclimatecorps.org/sites/default/files/4867_Santillietal_ClimaticChange.pdf. Acesso em: 15 jan. 2017.

SOARES FILHO, B. Impacto da revisão do Código Florestal: como viabilizar o grande desafio adiante? Desenvolvimento Sustentável, Subsecretaria SAE. 2013. Disponível em: https://www.socioambiental.org/ sites/blog.socioambiental.org/files/nsa/arquivos/artigo-codigo-florestal_britaldo_soares_sae_2013pdf. pdf. Acesso em: 14 jan. 2017.

STEFANES, M. et al. Property size drives differences in forest code compliance in the Brazilian Cerrado. Land Use Policy, vol. 75, 2018. p. 43-49.

YOUNG, C. E. F. (coord.). Estudos e produção de subsídios técnicos para a construção de uma Política Nacional de Pagamento por Serviços. Relatório Final. Rio de Janeiro: Instituto de Economia, UFRJ. 2016. p. 93. Disponível em: http://www.ie.ufrj.br/images/gema/Gema_Artigos/2016/relatorio_final_apendices. pdf. Acesso em: 14 jan. 2017.

YOUNG, C. E. F.; BAKKER, L. B. de. Payments for ecosystem services from watershed protection: a methodological assessment of the Oasis Project in Brazil. Natureza \& Conservação, v. 12, p. 71-78, 2014.

YOUNG, C. E. F. et al. Fundamentos econômicos da proposta de pacto nacional pela valorização da floresta e pelo fim do desmatamento na floresta amazônica. Relatório Final. 2007. Disponível em: http:// www.greenpeace.org/raw/content/brasil/documentos/amazonia/fundamentos-econ-micos-da-prop-2. pdf. Acesso em: 14 jan. 2017.

WAGNER, S. A. et al. (org.). Gestão e planejamento de unidades de produção agrícolas. Porto Alegre: Ed. da UFRGS, 2010. (Série educação a distância). Disponível em: http://www6.ufrgs.br/cursopgdr/downloadsSerie/derad015.pdf.

WUNDER, S. Payment for environmental services: Some nutsandbolts. CIFOR Occasional Paper n.42. Bogor: CIFOR. 2005. Disponível em: http://www.cifor.org/publications/pdf_files/OccPapers/OP-42.pdf. Acesso em: 14 jan. 2017. 